\title{
BMJ Open Effectiveness of three-dimensional printed and virtual reality models in learning the morphology of craniovertebral junction deformities: a multicentre, randomised controlled study
}

Siyi Cai, ${ }^{1}$ Yu He, ${ }^{2}$ Haomin Cui, ${ }^{3}$ Xi Zhou, ${ }^{1}$ Dongsheng Zhou, ${ }^{4}$ Fu Wang, ${ }^{4}$ Ye Tian (i) ${ }^{1}$

To cite: Cai S, He Y, Cui H, et al. Effectiveness of threedimensional printed and virtual reality models in learning the morphology of craniovertebral junction deformities: a multicentre, randomised controlled study. BMJ Open 2020;10:e036853. doi:10.1136/ bmjopen-2020-036853

- Prepublication history and additional material for this paper are available online. To view these files, please visit the journal online (http://dx.doi. org/10.1136/bmjopen-2020036853).

$\mathrm{SC}, \mathrm{YH}$ and $\mathrm{HC}$ contributed equally.

Received 07 January 2020 Revised 30 July 2020 Accepted 25 August 2020

Check for updates

(C) Author(s) (or their employer(s)) 2020. Re-use permitted under CC BY-NC. No commercial re-use. See rights and permissions. Published by BMJ.

For numbered affiliations see end of article.

Correspondence to

Professor Ye Tian;

tianye2019trail@163.com

\section{ABSTRACT}

Objectives To compare the effectiveness of threedimensional printed (3DP), virtual reality (VR) and conventional normal physical (NP) models in clinical education regarding the morphology of craniovertebral junction (CVJ) deformities.

Design Prospective, multicentre, randomised controlled study.

Setting Three teaching hospitals in China.

Participants Onehundred and fifty-three participants in their first year of a 3-year medical residency programme.

Interventions All participants were randomised to one of the three groups to learn the morphology of CVJ deformities using 3DP, VR or NP models.

Primary outcome measures The objective outcomes were evaluated using three-level objective testing. In the first-level test, the participants were required to identify 15 anatomical landmarks on radiographs without CVJ deformities. In the second-level test, all participants were asked to identify the same 15 landmarks on radiographs showing classic CVJ deformities. In the third-level test, the participants were required to describe the key features of three classic cases of CVJ deformities depicted on radiographs. Each participant was also asked to answer four subjective questions to evaluate the importance and usefulness of the educational materials.

Results In the first-level test, the 3DP, VR and NP groups achieved similar correct rates. In the secondlevel test, the correct rate was higher in the 3DP group $(82.1 \% \pm 13.6 \%)$ than the VR and NP groups $(76.9 \% \pm 16.9 \%$ and $69.9 \% \pm 20.0 \%, p=0.002)$. In the thirdlevel test, the 3DP group achieved better correct rates regarding the description of key CVJ deformities features $(66.2 \% \pm 20.0 \%, p=0.049)$ than the other groups. The subjective tests showed that the 3DP model method was considered the most valuable approach for learning CVJ deformities.

Conclusions The objective and subjective results show that the 3DP model is more effective teaching instrument than the NP model for learning the pathomorphology of CVJ deformities. The VR model also showed great
Strengths and limitations of this study

- The study used a multicentre, randomised controlled design to investigate the effectiveness of three-dimensional printed models as a learning instrument.

- Both objective and subjective tests were used to compare the impact of three-dimensional printed, virtual reality and conventional physical models on learning.

- Long-term retention during the learning process was not assessed.

- The scoring method was not weighted in accordance with the importance of the anatomical structures being identified.

- The lack of female participants led to the inability to judge the impact of sex on visuospatial ability.

efficacy, second to 3DP model, in improving participants' understanding of CVJ deformities.

\section{INTRODUCTION}

Craniovertebral junction (CVJ) deformity is a life-threatening disorder due to the associated neural compression, vascular compromise and instable cerebrospinal fluid dynamics. ${ }^{1}$ A wide range of embryological classification patterns have been reported, ${ }^{2}$ such as C1 sclerotome anomalies, basioccipital dysgeneses, proatlas anomalies and odontoid dysgeneses. The indication for surgical treatment of a CVJ deformity is symptomatic and clinical deterioration. ${ }^{13-6}$ Conventionally, accurate knowledge about the anatomical morphology usually accounts for the initial link between learning about and treating CVJ deformity, as the anatomy in the CVJ region is complex. This step is also important for surgeons in the diagnosis, treatment, fixation 
and decompression of CVJ deformities, particularly for novices. However, traditional clinical education alone cannot enable surgeons to comprehensively understand this complex anatomical deformity; the optimal anatomical morphologic education should be carried out from vision to touch, from plane to stereo and from physiology to pathology.

The gold standard method for teaching the characteristics of anatomical deformities is to train students in the context of actual surgery, as this involves tactile manipulation, direct interactions and the use of multiple senses. However, there are few suitable cases available for teaching purposes, and teaching may increase the risks of iatrogenic injury and surgical trauma, which creates ethical issues that limit the application of such a gold standard teaching method. The traditional teaching method comprises the use of textbooks, radiographs and three-dimensional (3D) reconstructed images and the conventional normal physical (NP) model has been applied for several years in bedside teaching. However, this conventional teaching method does not provide pathomorphological information with tactile feedback in actual cases of deformity, or enable the stereoscopic visualisation of anatomical structures. As educational technology develops, novel concepts and methods have been proposed to bridge this gap between actual clinical situations and traditional education.

Virtual reality (VR) technology is widely used in the teaching field as an effective learning instrument that improves visuospatial understanding. ${ }^{78}$ The VR equipment displays medical data in a virtual environment that provides immersive characteristics and a virtual real experience. The 3D-VR and multifunction head-mounted display system provides a reliable and convenient method to improve the understanding of complex anatomy structures, ${ }^{9-11}$ enhance visuospatial skills and bridge the gap between the textbook and clinical disease. Another learning instrument is the use of 3D printed (3DP) models, which is also known as the rapid prototyping method. The 3DP models are used for preoperative planning and intraoperative assistance, and as an educational tool that provides tactile feedback by directly recreating patient-specific features. ${ }^{12-14}$ Tactile feedback has been recognised as the interface between the real skeleton and the imaging data, and enables students to feel the fragment edges, textures, contours and resistance. ${ }^{15}$ In terms of haptics, it is important to comprehensively understand and preserve the spatial relationships and information. During the process of learning anatomical morphology, tactile input plays a critical role in effectively understanding the complicated structures of the CVJ region.

No study has compared 3DP and VR models with the NP models that are widely used for conventional learning about CVJ deformities. Furthermore, it is unknown whether it is feasible to use 3DP and VR models to teach students about deformities in the CVJ region, which is associated with the most complicated spinal morphology. Thus, the present study aimed to compare the effectiveness of using 3DP, VR and NP models to educate students about anatomical deformities of the CVJ. The new VR method was not proposed as a substitute for the traditional educational methods, but as an aid in bridging the gap between the actual clinical situation and traditional education. It was hypothesised that the 3DP and VR models would markedly enhance the visuospatial and anatomical knowledge of medical students regarding CVJ deformities.

\section{METHODS}

\section{Study design}

The current prospective, multicentre, randomised controlled trial was carried out from June 2018 to December 2018 in the following three teaching hospitals: Peking Union Medical College Hospital, Sixth People's Hospital Affiliated to Shanghai Jiao Tong University and Shandong Provincial Hospital Affiliated to Shandong University. The participants who were in their first year of the 3-year standardised resident training programme at the abovementioned three national training bases were invited to participate in the current study. The participants at this stage of medical training possess a fundamental understanding of neurosurgery, orthopaedics and general anatomy, but do not comprehensively understand CVJ deformities. Each participant was informed that our additional teaching was independent from their courses, and that their decision regarding participation in the present study would not influence the completion of their neurosurgical and orthopaedic courses. Each participant was evaluated regarding their visuospatial capacity and medical background. A total of 153 participants were recruited. Coincidentally, all of the participants in the present study were men. The participants were distributed into the 3DP, VR and NP learning groups $(n=51$ in each group) in accordance with the randomisation protocol. The three groups did not significantly differ regarding participant characteristics and medical background. The mean ages in the 3DP, VR and NP groups were 23.7 \pm 1.4 years, $24.0 \pm 1.5$ years and $23.9 \pm 1.6$ years, respectively.

\section{Learning groups}

The learning processes for the three groups were conducted separately. In the initial preparation process, all three groups attended a 60-min lecture on the fundamental knowledge of CVJ deformity; the lecture focussed on displaying the anatomical landmarks of the CVJ region, and introduced the spatial relationships among different landmarks in classic CVJ deformities. After attending the lecture, the participants in each group spent $30 \mathrm{~min}$ reviewing the information on CVJ deformities using textbooks, imaging data and instruments (figure 1).

The educational instruments of each group are briefly displayed in figure 2. The NP group felt the anatomical landmarks of the CVJ region on physical models, similar to the traditional learning approach. The NP model (Shanghai Medical Teaching Model Co, Ltd, China) was 


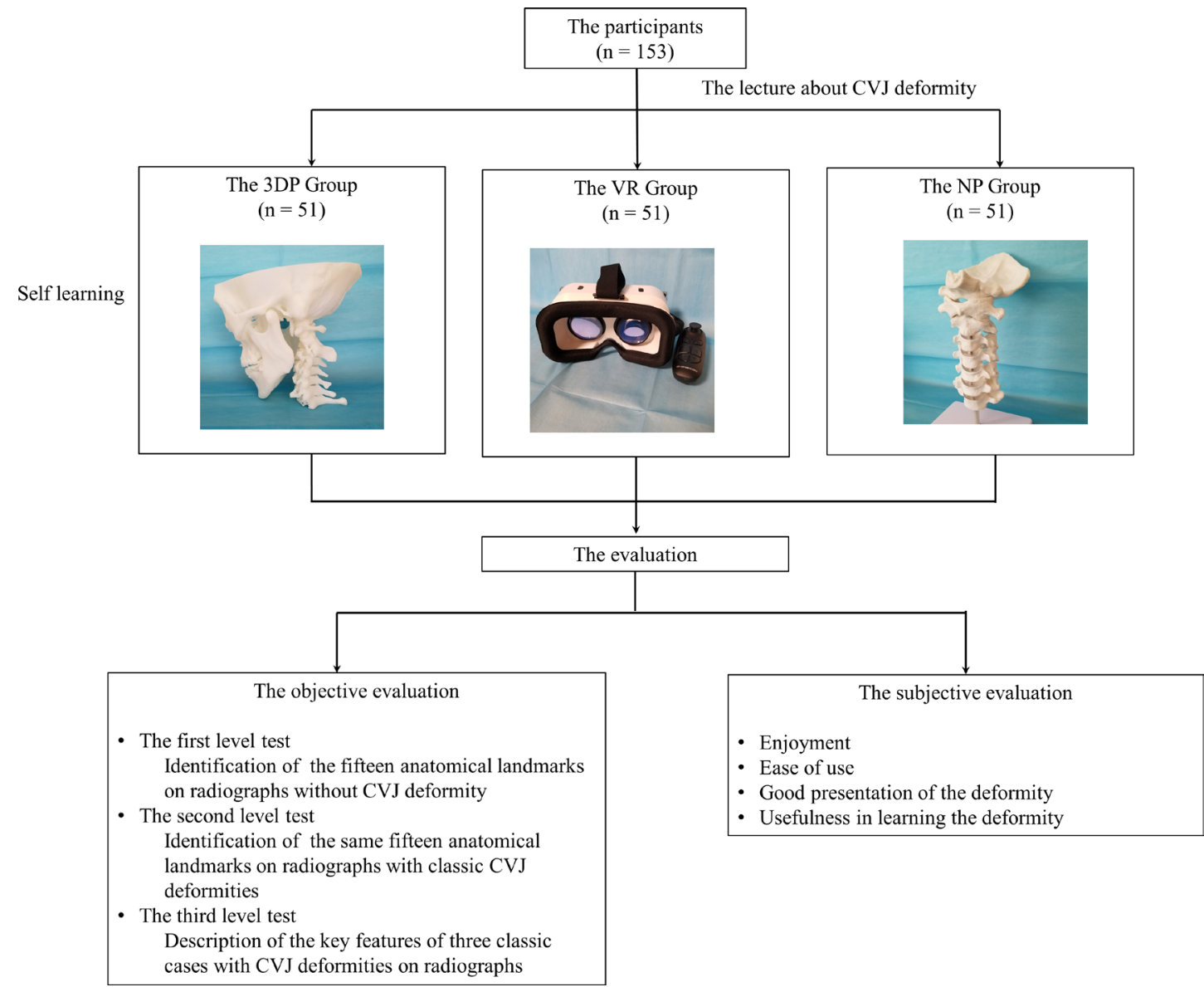

Figure 1 The concise experimental strategy of present study. CVJ, craniovertebral junction; NP, normal physical;VR, virtual reality; 3DP, three-dimensional printed.

made of plastic material, with normal anatomy in the CVJ region. In addition to the conventional teaching method, the VR group were provided with 3D digital models of the CVJ to assist in their learning. The VR models were prepared using CT reconstruction software (Mimics 15.0, Materialise, Belgium). The 3D data was inputted into a head-mounted display system (VR Shinecon, Shinecon Co Ltd, China) to show the CVJ deformities. The VR group used a remote control device to resize or rotate the VR models. In addition to the traditional learning approach, the 3DP group were provided with life-sized 3DP models of CVJ deformity for observation and touching. The same CT reconstruction data that was used to create the VR models were used to build 3DP models using a 3DP system (photopolymer resin, SLA660, Aidi Co, Ltd, China). The different models with different CVJ deformities were used in the teaching process, such as the free odontoid process, the atlantoaxial joint dislocation, abnormal vertebral fusion, basilar invagination with/without assimilation of atlas and proatlas anomalies. The free subunits of the 3DP models were connected with connecting rods during the manufacturing process to prevent changes in the spatial relationships.

\section{Evaluation}

After the completion of the learning process, the participants' knowledge regarding CVJ deformities was objectively and subjectively evaluated. The imaging data used in this evaluation process were distinct from those used in the initial learning process. Three-level testing was performed to assess the participants' knowledge regarding the morphology of CVJ deformities. In the first-level test, subjects were required to identify the following 15 anatomical landmarks on radiographs of subjects without CVJ deformities: occipital bone, foramen magnum, posterior fossa, atlas, anterior arch of the atlas, posterior arch of the atlas, lateral mass of the atlas, transverse foramen of the atlas, axis, odontoid process, transverse foramen of the epistropheus, atlantoaxial joint, cervical spinal cord, cerebellar tonsil and medulla oblongata. In the second-level test, all participants were asked to identify the same 15 landmarks on radiographs showing classic CVJ deformities. In the third-level test, the participants were required to describe the features of three cases of classic CVJ deformity depicted on radiographs; these radiographs were different from those used in the second-level test, and consisted of the most commonly used preoperative assessment approach. In the first-level and second-level tests, the participants scored one point for each correctly identified anatomical landmark. In the third-level test, the participants scored one point for each correctly identified key deformity, such as condylar hypoplasia, hemivertebrae and basilar invagination. 


\section{A \\ The 3DP Group}

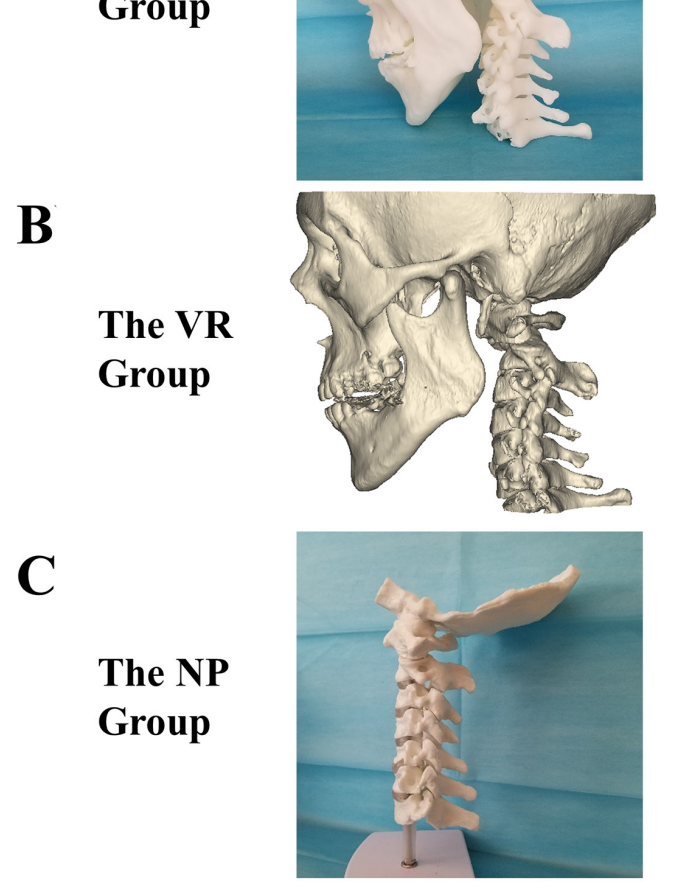

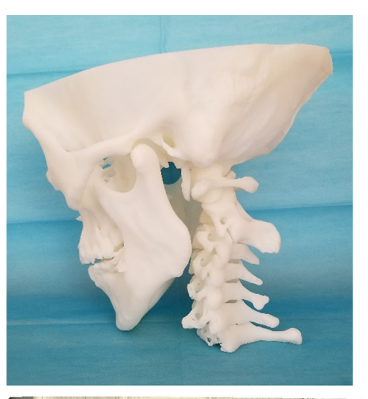
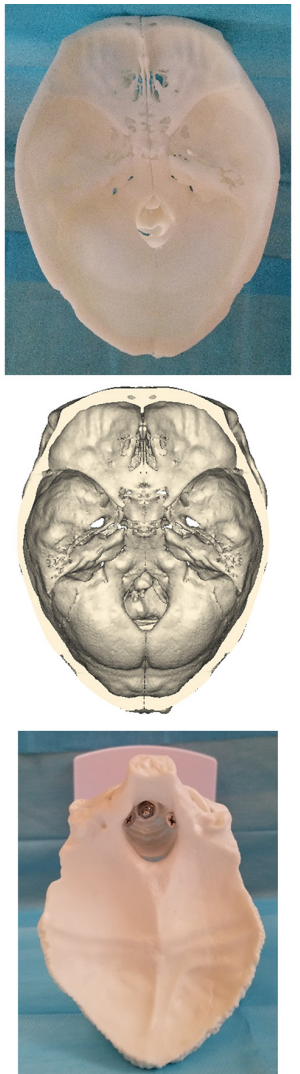
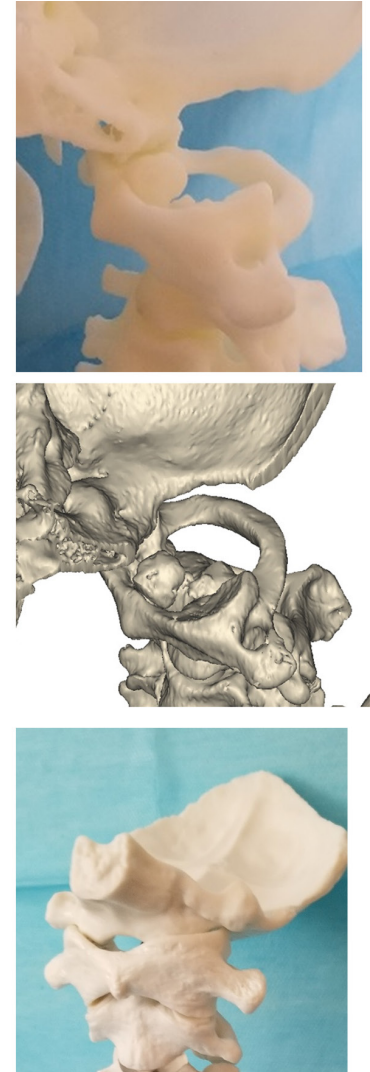

Figure 2 Example of the three-dimensional printed (3DP) model (A), the virtual reality (VR) model (B), and the normal physical (NP) model (C) was used on educating craniovertebral junction deformities morphology.

All three groups completed a learning instrumentrelated feedback questionnaire based on the 5-point Likert scale (strongly agree, agree, indifferent, disagree and strongly disagree). The questionnaire covered four areas (usefulness in learning the deformity, good presentation of the deformity, ease of use and enjoyment) regarding two topics (importance in understanding the deformity and usability of the learning material). The examples of questionnaires in objective and subjective evaluation are shown in online supplemental material 1.

\section{Statistical methods}

All statistical analyses were performed using SPSS 19.0 software (IBM Corp, Armonk, New York). The normality of distribution of the variables was analysed by the Kolmogorov-Smirnov test. The average values of the three groups were compared using analysis of variance testing. The Mann-Whitney U test was used to evaluate the subjective questionnaire results. Values of $p<0.05$ were considered to indicate statistically significant differences.

\section{Patient and public involvement}

No patient involved.

\section{RESULTS}

\section{Objective outcomes}

In the first-level test, the 3DP, VR and NP groups showed similar correct rates in the identification of anatomical landmarks of the CVJ $(83.1 \% \pm 12.7 \%, 83.0 \% \pm 11.4 \%$ and $84.3 \% \pm 11.9 \%$, respectively; $\mathrm{p}=0.833$; figure $3 \mathrm{~A}$ ).

In the second-level test, the 3DP and VR groups had higher correct rates in the identification of anatomical landmarks on radiographs of CVJ deformities $(82.1 \% \pm 13.6 \%$ and $76.9 \% \pm 16.9 \%$, respectively) than the $\mathrm{NP}$ group $(69.9 \% \pm 20.0 \%$; $\mathrm{p}=0.002$; figure $3 \mathrm{~B})$. Furthermore, the 3DP group achieved a better correct rate than the VR group. The anatomical landmarks that were most commonly incorrectly identified were the transverse foramen of the epistropheus, atlantoaxial joint and cerebellar tonsil.

In the third-level test, the VR and NP groups showed similarly poor scores in identifying the anatomical features of CVJ deformity $(58.8 \% \pm 23.2 \%$ and $57.4 \% \pm 24.0 \%$, respectively; figure 3C). In contrast, the 3DP group achieved better scores in this challenging question $(66.2 \% \pm 20.0 \%$; $\mathrm{p}=0.049$ ); however, only three participants in the 3DP group correctly identified every key deformity in each case. The deformities that were most commonly incorrectly identified were atlantoaxial subluxation, platybasia and occipitalisation. The deformities that were most commonly correctly identified were the free odontoid process and abnormal vertebral fusion.

\section{Subjective results}

Figure 4 shows the subjective questionnaire results. The feedback from the 3DP and VR groups showed that the 
A

The First Level Test

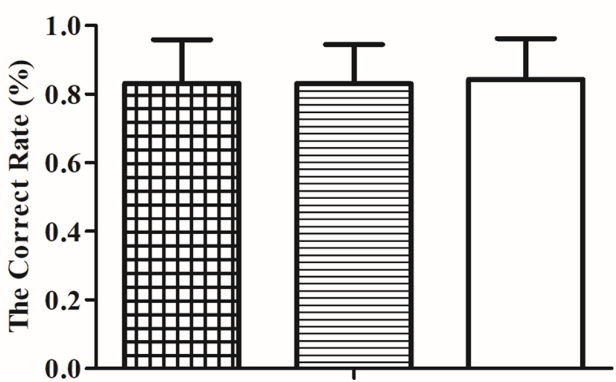

B

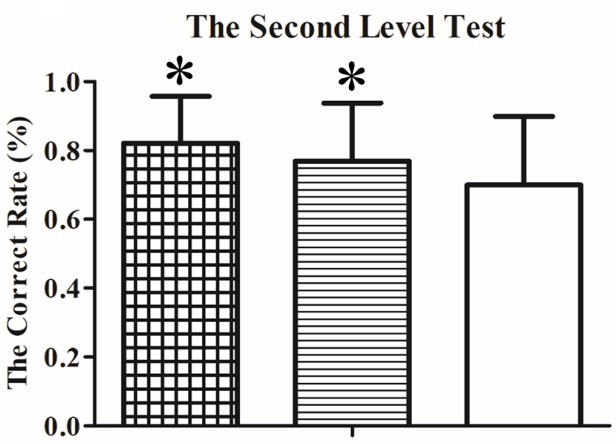

C The Third Level Test

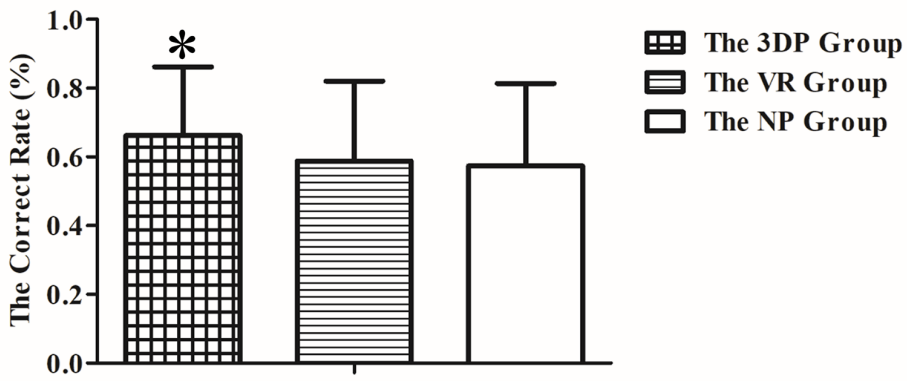

Figure 3 The results of recognising anatomical landmarks in normal (A) and craniovertebral junction deformities (B) radiographs. The accuracy of describing the key features of the CVJ deformities (C). ${ }^{*} p<0.05$, versus the NP group. CVJ, craniovertebral junction; NP, normal physical;VR, virtual reality; 3DP, three-dimensional printed.

participants thought that the supplemental tools provided a good presentation of the CVJ deformity and were useful in learning about the CVJ deformity. In particular, almost all participants from the 3DP group strongly agreed that the learning method was well presented and useful.
All participants from the three groups considered the supplemental tools easy to use. Typically, the 3DP models were considered the most enjoyable supplemental tool for the learning of CVJ deformity. In contrast, only $46.0 \%$

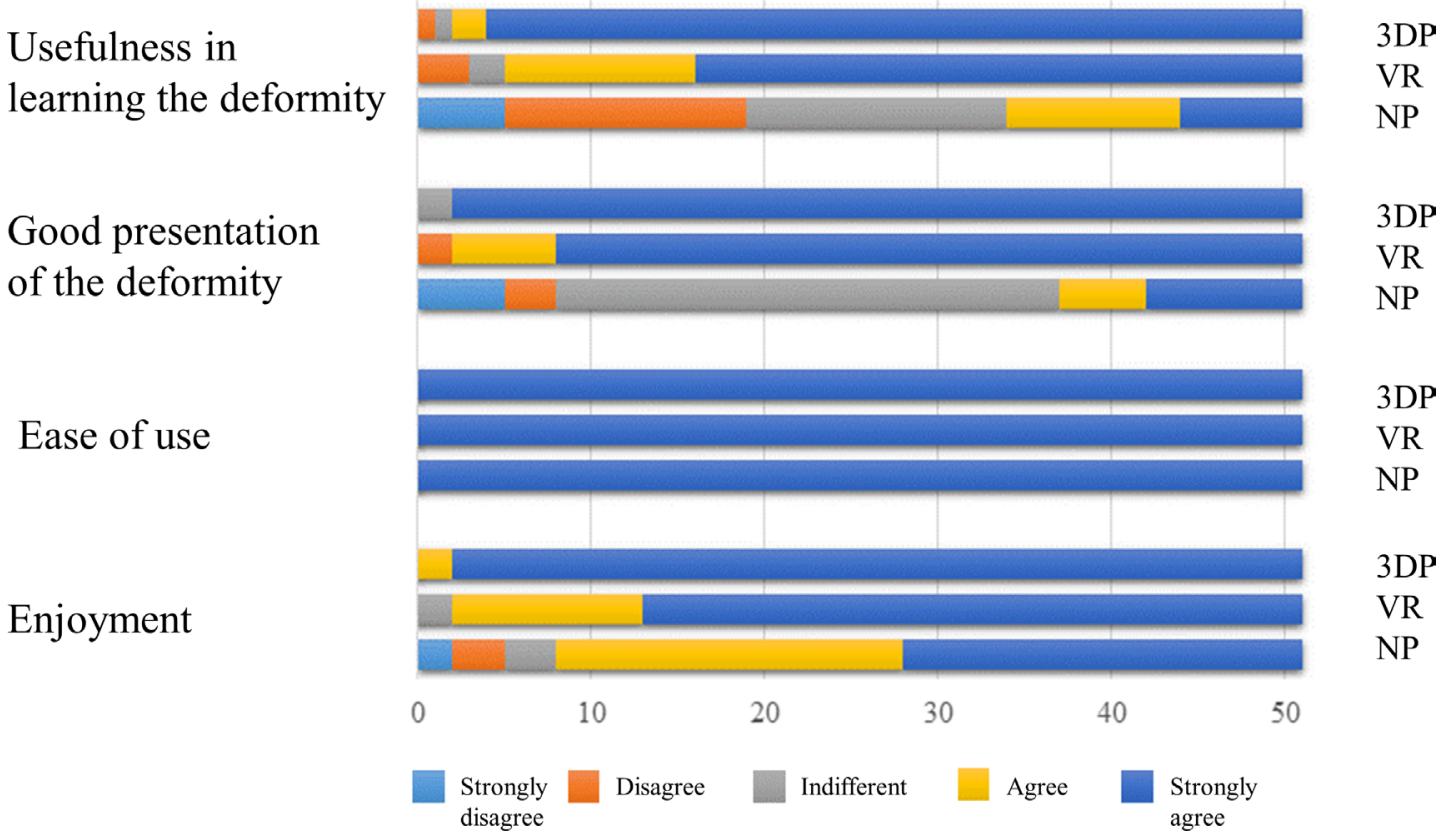

Figure 4 The results of the subjective feedback questionnaire. NP,normal physical; VR, virtual reality; 3DP, three-dimensional printed. 
of participants strongly agreed that the physical models were enjoyable.

\section{DISCUSSION}

Surgical treatment of CVJ anomalies remains a huge challenge for neurosurgeons, and requires accurate and detailed understanding of the anatomy in the CVJ region. The importance and complexity of the CVJ region, which is a vital pathway for the cerebral spinal cord, adds to the difficulties in learning about CVJ anomalies during medical training. Traditional education on CVJ deformities frequently combines textbook learning with the use of physical models of the normal CVJ region, which provides information on two-dimensional abnormal CVJ morphology and tactile feedback on normal conditions. However, there is still a gap between education and actual experience with deformity cases, particularly for complicated CVJ deformities. This gap may be bridged by the provision of tactile feedback of actual CVJ deformity and 3D morphology. New technology may help to bridge this gap, and can also be used to precisely reconstruct the anatomical structures stereoscopically based on CT scans.

In the conventional hands-on radiologic education, which is currently still in use, only the patients' images are displayed. This method is effective in assisting students in learning the simple anatomical features, but is not adequate for learning about complex anatomical areas, like the CVJ region. To make up for this shortage, an increasing number of new methods are being employed in modern education. The 3DP and VR are considered the best supplementary tools for learning about complex anatomical structures. VR technology has had a profound impact on numerous traditional industries, including information technology, industrial design, entertainment and surgery. ${ }^{716}$ Many VR devices are used in medical education, such as SynDaver, Synthetic Tissue Simulator and Microsoft Hololens. ${ }^{9}$ The immersive characteristics and virtual real experience improves the quality of training, preoperative workup and augmented reality intraoperatively. ${ }^{9}{ }^{10}$ In surgical training, VR offers visual feedback, especially in the training of laparoscopic surgical techniques. Ammanuel et al created four educational 3D anatomy models (skull, spine, vertebral aneurysm and circle of Willis) that could be controlled in rotational and translational dimensions. ${ }^{7}$ They believed that the visualisation of $3 \mathrm{D}$ anatomical structures increases the educational interactivity of students, which serves as a powerful teaching tool. Other studies illustrate that VR increases the understanding of anatomical structures and spatial relationships. ${ }^{17}$ Brouwers et al used mobile 3D-VR headsets and 3DP models to classify acetabular fractures, and first reported the value of $3 \mathrm{D}-\mathrm{VR}$ headsets in surgical training with several levels; they found that 3D-VR technology is valuable in understanding acetabular fractures, but is inferior to the use of 3DP models. ${ }^{11}$ The present study found that VR was an effective approach to enhance the learning ability. We believe that the lack of tactile feedback limited the learning in the VR group in our study.

The progression of educational technology has brought new learning methods that are able to provide surgical trainees with tactile feedback. Specifically, the VirtualFracture Carving Simulator based on tactile sensation aids in the understanding of the anatomy of acetabular fractures in a spatial manner by plotting lines onto the virtual models. ${ }^{19}$ Such interactive systems are considered to improve the learning of complex anatomical structures. Several scholars consider the use of 3DP models as a promising method for clinical education. Goel et al first reported the use of 11 life-sized 3DP CVJ models for training and surgical assistance; the authors believed that 3DP models provide meaningful information for CVJ surgery and are a useful education tool for medical students and residents. ${ }^{20}$ The $3 \mathrm{DP}$ technology is also widely used in other disciplines. A multicentre, randomised controlled study found that 3DP modelling of actual fractures is an effective learning approach for understanding acetabular fracture morphology and promoting subjective interest. ${ }^{21}$ Another study that examined the effectiveness of 3DP models in teaching the complicated spatial relationships of the equine foot revealed that 3DP models are superior to textbooks in enhancing the visuospatial understanding. ${ }^{22}$ Furthermore, an actual elastic aneurysm model based on 3DP modelling is reportedly valuable in enabling students to understand the complicated aneurysm structures when used in surgical training and simulation. ${ }^{23}$ Moreover, the application of lifelike 3DP models dramatically enhances the teaching of spinal fracture anatomy, ${ }^{24}$ which is consistent with the results of the present study. Our objective assessment results showed that the 3DP group achieved a better correct rate in identifying CVJ landmarks than the NP group. Moreover, the 3DP group showed a higher capacity to identify CVJ deformities on radiographs from real cases.

In the learning process, the subjective initiative is an important factor that enhances the effectiveness of learning. Several studies have shown that surgical trainees respond positively to the usability of 3DP and VR models as learning materials. ${ }^{212526}$ A similar outcome was identified in the present study, in which the 3DP and VR models were considered better and more favourable learning tools than the NP models. Specifically, 96.1\% of the participants in the present study strongly agreed that the 3DP and VR models were enjoyable. We believe that this enjoyment transformed into a positive attitude towards learning the complex CVJ anatomy. In addition, the 3DP and VR models attained a better subjective assessment of the presentation of the CVJ deformity and usefulness in learning the CVJ deformity. This might be explained by the fact that the 3DP and VR models provided more vivid pathomorphology compared with the standardised physiological morphology provided by the NP models.

The present study had some limitations. First, the longterm retention of the anatomy of CVJ deformity was not evaluated. However, the aim of the present study was to 
evaluate the improvements in the understanding of the anatomy of this complex region, rather than the improvements in memorising the anatomical features. Furthermore, more knowledge and a positive attitude generally facilitates long-term retention of information. Second, different anatomical landmarks have differing levels of importance in the identification of CVJ deformities. However, the scoring process did not involve weighting of the anatomical landmarks in accordance with their importance. In advanced education, it is very important to understand the significance of different anatomical landmarks. However, the present study was only designed to evaluate the effectiveness of three kinds of models in the clinical education of junior students regarding the morphology of CVJ deformities. This limitation may be solved in further studies by the use of a weighted scoring system. Third, previous studies have reported a difference in visuospatial capacity between sexes. ${ }^{27} 28$ However, all participants in the present study happened to be men coincidentally, which made it impossible to judge the effect of sex on the visuospatial capacity. Further studies with sex-balanced study populations are needed to investigate this issue. Fourth, voluntary participants might achieve lower test scores due to lower levels of motivation compared with students who are undertaking a mandatory part of their training programme; this bias might be minimised by the use of a multicentre, randomised controlled protocol.

In conclusion, the CVJ is an extremely complex anatomical region with spatial relationships that are challenging to understand. We consider that the optimal anatomical learning pattern should follow the following process: from physiology to pathology, from plane to stereo and from vision to touch. The traditional education pattern based on textbooks and physical models cannot provide tactile feedback and stereoscopic pathomorphology. As complementary tools, we believe that 3DP and VR models are effective in enhancing the understanding of spatial relationships for junior students by providing tactile feedback and 3D pathomorphology of the CVJ region.

\section{Author affiliations}

${ }^{1}$ Orthopaedic Surgery, Peking Union Medical College Hospital, Beijing, China ${ }^{2}$ Surgery, Chinese Academy of Medical Sciences \& Peking Union Medical College Plastic Surgery Hospital and Institute, Shijingshan District, Beijing, China ${ }^{3}$ Orthopedic Surgery, Shanghai Jiaotong University Affiliated Sixth People Hospital South Campus, Shanghai, China

${ }^{4}$ Orthopaedic Surgery, Shandong Provincial Hospital, Jinan, Shandong, China

Acknowledgements We thank all participants who participated in this study. We thank Kelly Zammit, BVSc, from Liwen Bianji, Edanz Editing China, for editing the English text of a draft of this manuscript.

\section{Collaborators N/A}

Contributors YT, FW and DZ conceived the study idea. SC, HC and YH performed the literature search. XZ, HC, DZ and YH were involved in data collection. SC, HC and $\mathrm{YH}$ wrote the first draft of the manuscript. YT and FW critically revised the manuscript. All authors approved the final versions of the manuscript. YT and FW take responsibility for the integrity of the data and the accuracy of the data analysis.

Funding This work was supported by the Science and Technology Development Program of Shandong Province (No. 2015GSF118110).
Competing interests None declared.

Patient and public involvement Patients and/or the public were not involved in the design, or conduct, or reporting, or dissemination plans of this research.

Patient consent for publication Not required.

Ethics approval All experimental protocols were approved by the Institutional Review Board of Peking Union Medical College Hospital (No. S-K189). Authors obtained verbal informed consent from all subjects to participate in this study.

Provenance and peer review Not commissioned; externally peer reviewed.

Data availability statement Data are available upon reasonable request.

Open access This is an open access article distributed in accordance with the Creative Commons Attribution Non Commercial (CC BY-NC 4.0) license, which permits others to distribute, remix, adapt, build upon this work non-commercially, and license their derivative works on different terms, provided the original work is properly cited, appropriate credit is given, any changes made indicated, and the use is non-commercial. See: http://creativecommons.org/licenses/by-nc/4.0/.

ORCID iD

Ye Tian http://orcid.org/0000-0001-5061-7998

\section{REFERENCES}

1 Menezes $\mathrm{AH}$. Craniocervical developmental anatomy and its implications. Childs Nerv Syst 2008;24:1109-22.

2 Pang D, Thompson DNP. Embryology and bony malformations of the craniovertebral junction. Childs Nerv Syst 2011;27:523-64.

3 Goel A, Sathe P, Shah A. Atlantoaxial fixation for basilar invagination without obvious atlantoaxial instability (group B basilar invagination): outcome analysis of 63 surgically treated cases. World Neurosurg 2017;99:164-70.

4 Milhorat TH, Chou MW, Trinidad EM, et al. Chiari I malformation redefined: clinical and radiographic findings for 364 symptomatic patients. Neurosurgery 1999;44:1005-17.

5 Joaquim AF, Tedeschi H, Chandra PS. Controversies in the surgical management of congenital craniocervical junction disorders - A critical review. Neurol India 2018;66:1003-15.

6 Joaquim AF, Ghizoni E, Giacomini LA, et al. Basilar invagination: surgical results. J Craniovertebr Junction Spine 2014;5:78-84.

7 Ammanuel S, Brown I, Uribe J, et al. Creating 3D models from radiologic images for virtual reality medical education modules. $J$ Med Syst 2019;43:166.

8 Khot Z, Quinlan K, Norman GR, et al. The relative effectiveness of computer-based and traditional resources for education in anatomy. Anat Sci Educ 2013;6:211-5.

9 Bernardo A. Virtual reality and simulation in neurosurgical training. World Neurosurg 2017;106:1015-29.

10 Izard SG, Juanes JA, García Peñalvo FJ, et al. Virtual reality as an educational and training tool for medicine. J Med Syst 2018;42:50.

11 Brouwers L, Pull Ter Gunne AF, de Jongh MA, et al. What is the value of $3 D$ virtual reality in understanding acetabular fractures? Eur $J$ Orthop Surg Traumatol 2020;30:109-16.

12 Fadero PE, Shah M, dimensional T. Three dimensional (3D) modelling and surgical planning in trauma and orthopaedics. Surgeon 2014;12:328-33.

13 Malik HH, Darwood ARJ, Shaunak S, et al. Three-Dimensional printing in surgery: a review of current surgical applications. J Surg Res 2015;199:512-22.

14 Marro A, Bandukwala T, Mak W. Three-Dimensional printing and medical imaging: a review of the methods and applications. Curr Probl Diagn Radiol 2016;45:2-9.

15 Minogue J, Jones MG. Haptics in education: exploring an Untapped sensory modality. Rev Educ Res 2006;76:317-48.

16 Bekelis K, Calnan D, Simmons N, et al. Effect of an immersive preoperative virtual reality experience on patient reported outcomes: a randomized controlled trial. Ann Surg 2017;265:1068-73.

17 Codd AM, Choudhury B. Virtual reality anatomy: is it comparable with traditional methods in the teaching of human forearm musculoskeletal anatomy? Anat Sci Educ 2011;4:119-25.

18 Das S, Mitchell P. Comparison of three AIDS for teaching lumbar surgical anatomy. Br J Neurosurg 2013;27:475-8.

19 Pahuta MA, Schemitsch EH, Backstein D, et al. Virtual fracture carving improves understanding of a complex fracture: a randomized controlled study. J Bone Joint Surg Am 2012;94:e182.

20 Goel A, Jankharia B, Shah A, et al. Three-Dimensional models: an emerging investigational revolution for craniovertebral junction surgery. J Neurosurg Spine 2016;25:740-4. 
21 Huang Z, Song W, Zhang Y, et al. Three-Dimensional printing model improves morphological understanding in acetabular fracture learning: a multicenter, randomized, controlled study. PLoS One 2018;13:e0191328.

22 Preece D, Williams SB, Lam R, et al. 'Let's get physical': advantages of a physical model over 3D computer models and textbooks in learning imaging anatomy. Anat Sci Educ 2013;6:216-24.

23 Mashiko T, Otani K, Kawano R, et al. Development of threedimensional hollow elastic model for cerebral aneurysm clipping simulation enabling rapid and low cost prototyping. World Neurosurg 2015;83:351-61.

$24 \mathrm{Li} \mathrm{Z,} \mathrm{Li} \mathrm{Z,} \mathrm{Xu} \mathrm{R,} \mathrm{et} \mathrm{al.} \mathrm{Three-dimensional} \mathrm{printing} \mathrm{models} \mathrm{improve}$ understanding of spinal fracture--A randomized controlled study in China. Sci Rep 2015;5:11570.
25 Lynch TG, Steele DJ, Johnson Palensky JE, et al. Learning preferences, computer attitudes, and test performance with computer-aided instruction. Am J Surg 2001;181:368-71.

26 McNulty JA, Sonntag B, Sinacore JM. Evaluation of computer-aided instruction in a gross anatomy course: a six-year study. Anat Sci Educ 2009;2:2-8.

27 Beermann J, Tetzlaff R, Bruckner T, et al. Three-Dimensional visualisation improves understanding of surgical liver anatomy. Med Educ 2010;44:936-40.

28 Masters MS, Sanders B. Is the gender difference in mental rotation disappearing? Behav Genet 1993;23:337-41. 